\title{
POTENCIAL HEPATOPROTETOR DAS PLANTAS MEDICINAIS DA RENISUS: REVISÃO SISTEMÁTICA
}

\section{Diorge Jônatas Marmitta , Claudete Rempel ${ }^{\mathrm{b}}$, Amanda do Couto e Silva ${ }^{\mathrm{c}}$, Márcia Inês Goettert ${ }^{\mathrm{d}}$}

adiorgemarmitt@yahoo.com.br, ${ }^{b}$ crempel@univates.br, camanda_do_couto_e_silva@hotmail.com, ${ }^{d}$ marcia.goettert@univates.br Centro Universitário UNIVATES - Lajeado (RS), Brasil

Data de recebimento do artigo: 03/12/2015 Data de aceite do artigo: 07/03/2016

\section{RESUMO}

Introdução: A lesão ou disfunção hepática é considerada um grave problema de saúde. Os medicamentos sintéticos disponíveis para tratar doenças hepáticas são caros e podem causar efeitos adversos com uso prolongado. Assim, os efeitos hepatoprotetores de plantas têm sido investigados. Objetivos: Quantificar as pesquisas que referem potencial terapêutico sobre doenças hepáticas a partir do estudo com plantas da RENISUS, publicados entre 2010 e fevereiro de 2013 em duas bases de dados científicas (SciELO e Science Direct) e uma editora de revistas científicas, Springer. Metodologia: A busca inicial resultou na seleção de 21.357 artigos encontrados nas bases de dados. A análise foi realizada primeiramente a partir da leitura do título das publicaçóes. Os artigos selecionados nessa etapa foram avaliados por meio da leitura do abstract. Por fim, foi lido integralmente o texto dos artigos selecionados na etapa anterior, tendo sido selecionados estudos pré-clínicos e clínicos que comprovaram potencial terapêutico hepatoprotetor. Resultados: Esta seleçáo resultou em 13 artigos de interesse, dos quais cinco estudos foram realizados com a planta Curcuma longa. Conclusóes: Os resultados propiciam subsídios teóricos para discussões no campo da Saúde Pública sobre tratamentos alternativos à base de plantas medicinais como um coadjuvante terapêutico. Nesse sentido, a correta utilização dessas plantas, somada à terapia convencional, pode contribuir para a melhora da saúde de pacientes com transtornos hepáticos.

Palavras-chave: Fígado; hepatite; plantas medicinais; atenção primária à saúde.

\section{ABSTRACT}

Introduction: The injury or liver dysfunction is considered a serious health problem. Synthetic drugs available to treat liver diseases are expensive and can cause adverse effects with prolonged use. Thus, the hepatoprotective effects of plants have been investigated. Objectives: To quantify the research that refer therapeutic potential for liver diseases from the study with RENISUS plants, published between 2010 and February 2013 in two scientific databases (SciELO and Science Direct) and one publisher of scientific journals, Springer. Methodology: The initial search resulted in the selection of 21,357 articles found in the databases. The analysis was first carried out from reading the title of publications. The articles selected in this step were evaluated by reading the abstracts. Finally, the texts of the articles selected in the previous step were read in their entirety, having been selected pre-clinical and clinical studies which have shown hepatoprotective therapeutic potential. Results: This selection resulted in 13 articles of interest, of which five studies were conducted with the Curcuma longa plant. Conclusions: The results provide theoretical basis for discussions in the field of Public Health on alternative treatments based on medicinal plants as a therapeutic adjuvant. In this sense, the correct use of these plants, added to conventional therapy, can help improve the health of patients with liver disorders.

Keywords: Liver; hepatitis; medicinal plants; primary health care. 


\section{Introdução}

O fígado é um dos mais importantes órgãos do corpo, pois desempenha um papel fundamental na regulação de diversos processos fisiológicos e a sua atividade está relacionada a diferentes funçôes, tais como o metabolismo, secreção e armazenamento de vitaminas. Realiza processos de desintoxicação de substâncias, seja por via endógena (metabolitos de resíduos) ou exógena (compostos tóxicos), e é capaz de sintetizar agentes úteis ${ }^{1}$.

Além disso, a bile, secretada pelo fígado, tem, entre outras funções, um papel importante na digestão. Por causa de todas essas funções, doenças hepáticas continuam entre as principais ameaças à saúde pública em nível global. As principais formas de doenças que acometem o fígado humano são a hepatite, aguda ou crônica (doenças inflamatórias do fígado); cirrose (doença degenerativa que resulta em fibrose do fígado); e hepatosis (doenças não inflamatórias) ${ }^{2}$.

Doenças do fígado são principalmente causadas por consumo excessivo de álcool; infecçôes e desordens autoimunes; produtos químicos tóxicos (antibióticos, quimioterápicos etc. $)^{2}$.

A maioria dos danos ocasionados às células do fígado é provocada por agentes químicos hepatotóxicos, principalmente por indução de peroxidação lipídica e danos oxidativos, podendo resultar em hepatite e cirrose ${ }^{3}$.

Estima-se que 240 milhões de pessoas são cronicamente infectadas com hepatite ${ }^{4}$. Mais de 780.000 pessoas morrem anualmente devido a complicaçóes da hepatite, incluindo cirrose e câncer de fígado 5 . Infelizmente, os tratamentos convencionais para doenças hepáticas são, em muitas situaçóes, insuficientes e, por vezes, causam graves efeitos secundários ${ }^{2}$.

O uso prolongado de paracetamol ou mesmo a ingestáo de altas doses desse medicamento é conhecido por causar hepatotoxicidade em humanos e animais. Isto se deve ao aumento da peroxidação lipídica no fígado, característica que causa a hepatotoxicidade, relacionada à administração dessa substância ${ }^{6}$. O estresse oxidativo é um dos mecanismos envolvidos na indução da hepatotoxicidade, o que provoca a desintegração da membrana e necrose ${ }^{7}$. O consumo excessivo de álcool está associado ao excesso de gordura nas células parenquimatosas, $o$ que provoca a morte das células do fígado 6 .

Apesar dos enormes avanços na medicina moderna, náo existem medicamentos completamente eficazes que estimulem a função hepática, ofereçam proteção completa para o fígado ou, ainda, auxiliem a regeneração de células hepáticas. Além disso, alguns medicamentos podem induzir severos efeitos colaterais. Assim, se faz necessário identificar alternativas terapêuticas mais eficazes e menos tóxicas para o tratamento de doenças hepáticas ${ }^{8}$.
Nesse sentido, a utilizaçáo de plantas e o consumo de frutas desempenharam papéis fundamentais na área da saúde humana. As plantas têm desempenhado um papel essencial na busca por novos compostos para os mais diversos fins terapêuticos. Um estudo publicado recentemente por Newman e Cragg ${ }^{9}$ mostrou que 50\% dos medicamentos aprovados no ano de 2010 foram direta ou indiretamente derivados de produtos naturais, entre os quais as plantas são os mais pesquisados.

Desde 2007, o sistema público de saúde do Brasil iniciou a oferta de fitoterápicos derivados de plantas. Atualmente, o Ministério da Saúde (MS) disponibiliza a utilização de 12 medicamentos fitoterápicos na rede pública de saúde, derivados de plantas que foram posteriormente inseridas na Relação Nacional de Plantas Medicinais de Interesse ao Sistema Único de Saúde (RENISUS) ${ }^{10}$, publicada em fevereiro de 2009. A lista é constituída por 71 espécies vegetais, entre as quais estão inseridas plantas utilizadas pelo uso empírico e aquelas cujos efeitos foram comprovados cientificamente. Do mesmo modo, foi priorizada a inclusão de plantas nativas dos diversos biomas do país e que possibilitassem atender às doenças mais comuns nos brasileiros ${ }^{11}$.

Em vista disso, constitui-se o objetivo da realização desta pesquisa, elaborar uma revisão sistemática a fim de apontar a quantidade de artigos científicos publicados sobre as plantas da lista da RENISUS com potencial hepatoprotetor, disponíveis em duas bases de dados científicas: Science Directe Scientific Electronic Library Online (SciELO), e uma editora de revistas científicas, Springer.

\section{Metodologia}

A pesquisa bibliográfica foi estruturada por meio de uma revisão sistemática acerca da produção científica das espécies vegetais da RENISUS. Para tanto, foram analisados e selecionados artigos científicos a partir da criação da RENISUS publicados no período de janeiro de 2010 a fevereiro de 2013 nas bases de dados supracitadas. Na consulta, foram considerados todos os artigos científicos disponibilizados, como texto completo e gratuito nas bases de pesquisa, independentemente do idioma de publicação.

Os descritores utilizados na consulta nas bases de dados foram os nomes científicos das plantas medicinais conforme informados na RENISUS.

O critério de inclusão dos artigos para análise foi a comprovação, em fase pré-clínica ou clínica, do potencial hepatoprotetor, a partir da pesquisa com planta(s) da RENISUS. Foram excluídos artigos de revisão e estudos que abordavam apenas a elucidação dos metabólitos secundários das plantas, sem o intuito de demonstrar potencial terapêutico. Excluíram-se, também, artigos 
que mencionavam somente o uso empírico das plantas, além de trabalhos realizados a partir de entrevistas semiestruturadas. Destaca-se que foram contabilizados apenas uma vez os artigos repetidos nas bases de dados.

Os dados coletados foram armazenados em disco rígido (Hard Disk). Para o acesso ao texto completo, foi digitado o link disponível da publicação na própria base de dados selecionada.

A análise das publicaçóes coletadas foi realizada em três etapas (Figura 1). Inicialmente, foram lidos todos os títulos dos artigos encontrados nas bases de dados, tendo sido selecionados os que apresentaram termos relacionados com potencial hepatoprotetor, como "hepatite", "hepatites", "fígado", "liver", "cirrose", "cirrhosis", "hepatosis", "hepatocelular", "hepatocellular", "hepatoprotetor", "hepatoprotective", "bile", "hepático", "hepatic", "hepatotóxico", "hepatotoxic", "úlcera", "ulcer". Terminada a análise das publicaçóes nessa fase, partiu-se para a segunda etapa, a qual se constituiu na leitura dos abstracts. Foram selecionados para a terceira fase de avaliação os artigos que mencionavam alguma forma de atividade hepatoprotetora a partir do estudo com as plantas de interesse. Por fim, no terceiro e último estágio do estudo, foram lidos e avaliados os textos integrais dos artigos selecionados na segunda etapa, sendo essa análise qualitativa.

Figura 1: Fluxograma das etapas da seleção dos artigos de interesse.

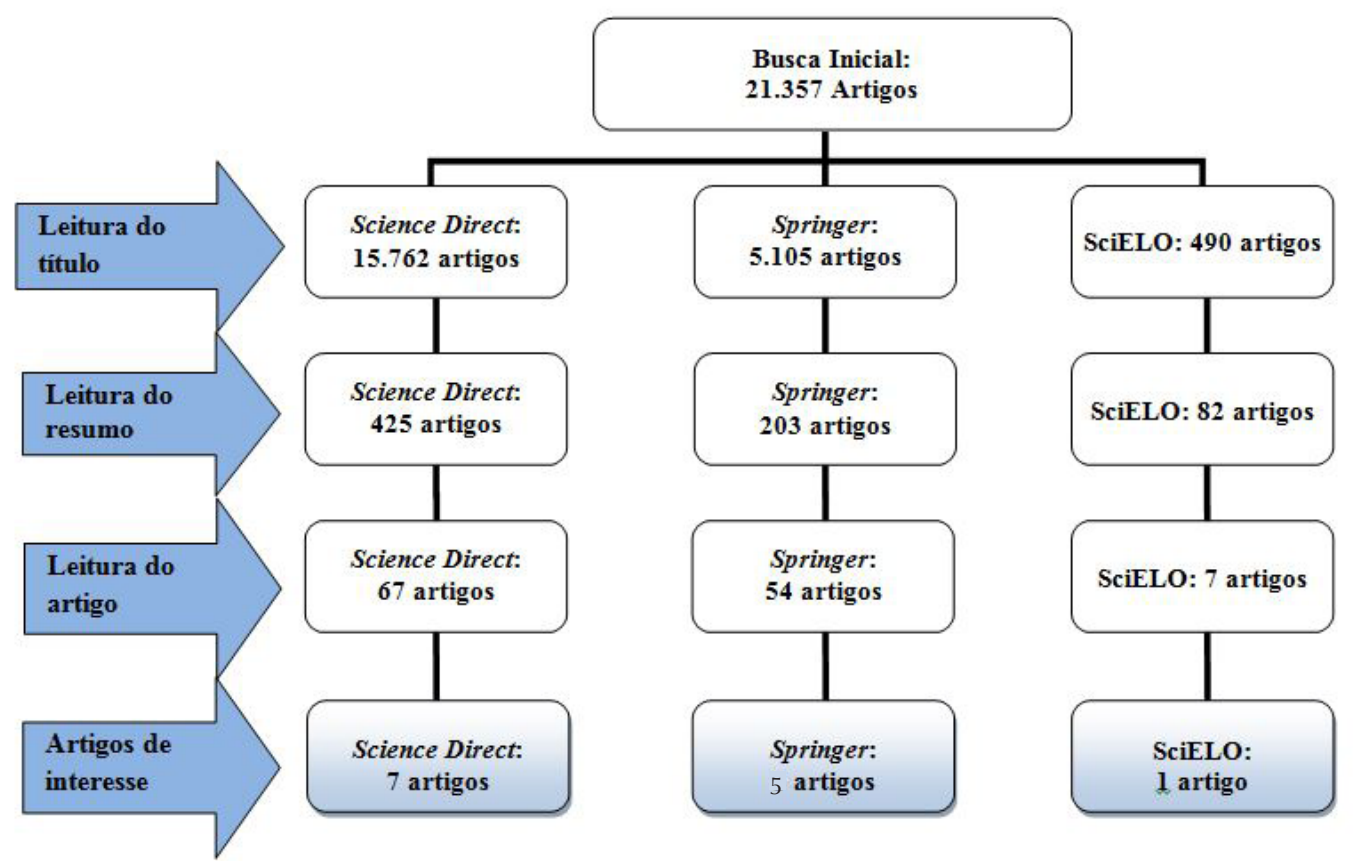

Fonte: Dados da pesquisa, 2015.

\section{Resultados}

A busca inicial pelos artigos partiu da leitura dos títulos das 21.357 publicaçōes distribuídas nas três bases de dados pesquisadas, resultando na seleção de 710 publicaçóes que tinham relação com potencial hepatoprotetor.

A seguir, leu-se o abstract desses 710 artigos, tendo sido excluídos 582 artigos que não apresentaram resultados que demonstrassem atividade hepatoprotetora. Os 128 trabalhos restantes foram lidos na íntegra, sendo que houve uma atenção maior à abordagem dos resultados a fim de evidenciar quais trabalhos, de fato, comprovaram potencial terapêutico a partir do estudo de plantas da RENISUS.
Por fim, o estudo selecionou e se concentrou em 13 artigos de interesse. A Tabela 1 informa a quantidade de artigos analisados e selecionados em cada base de dados, por planta medicinal de interesse.

Do total de artigos de interesse selecionados, um trabalho foi publicado no ano de 2010; dois, em 2011; sete, em 2012; três estudos foram realizados em 2013. Dos 13 estudos, uma pesquisa foi desenvolvida por pesquisadores brasileiros: Pereira et al. ${ }^{12}$.

As plantas citadas na Tabela 1 foram as que tiveram estudos relacionados ao efeito hepatoprotetor, publicados nas bases de dados consultadas. Das 71 espécies da lista da RENISUS, para seis espécies foram encontrados trabalhos dentro do escopo da pesquisa. Destas seis plantas com atividade hepatoprotetora, duas espécies 
são disponibilizadas no Sistema Único de Saúde como fitoterápicos: Cynara scolymus (alcachofra) e Glycine max (isoflavona-de-soja).

Avaliamos, ainda, as atividades terapêuticas às quais o potencial hepatoprotetor está associado (Tabela 2).
Os estudos mencionados foram realizados in vitro, envolvendo linhagens celulares, ou in vivo, em animais. Dentre as 13 publicaçóes, 12 pesquisas estão descritas no idioma inglês, e um trabalho está publicado em português ${ }^{12}$.

Tabela 1: Total de artigos analisados e selecionados somente com as plantas que apresentaram potencial hepatoprotetor.

\begin{tabular}{|c|c|c|c|c|c|c|c|c|}
\hline $\begin{array}{l}\text { Lista de espécies } \\
\text { citadas no RENISUS } \\
\text { (atualizaçáo APG III) }\end{array}$ & $\begin{array}{r}\text { Scienc } \\
\text { Analisados }\end{array}$ & $\begin{array}{l}\text { ce Direct } \\
\text { Selecionados }\end{array}$ & Analisados & $\begin{array}{l}\text { ringer } \\
\text { Selecionados }\end{array}$ & Analisados & Selecionados & $\begin{array}{r}\text { TO } \\
\text { Analisados }\end{array}$ & $\begin{array}{l}\text { TAL } \\
\text { Selecionados }\end{array}$ \\
\hline Allium sativum $\mathrm{L}$. & 863 & 2 & 198 & 0 & 12 & 0 & 1.073 & 2 \\
\hline Curcuma longa L. & 847 & 2 & 282 & 3 & 10 & 0 & 1.139 & 5 \\
\hline Cynara scolymus L. & 152 & 0 & 50 & 1 & 2 & 0 & 204 & 1 \\
\hline Glycine $\max$ (L.) Merr. & 2287 & 1 & 538 & 0 & 62 & 0 & 2.887 & 1 \\
\hline Momordica charantia L. & 376 & 2 & 0 & 0 & 25 & 1 & 401 & 3 \\
\hline Punica granatum L. & 527 & 0 & 120 & 1 & 6 & 0 & 653 & 1 \\
\hline TOTAL & 15.763 & 7 & 5.105 & 5 & 490 & 1 & 21.357 & 13 \\
\hline
\end{tabular}

Fonte: Dados da pesquisa, 2015.

Tabela 2: Estudos de interesse divididos por atividade terapêutica.

\begin{tabular}{|c|c|c|c|c|c|}
\hline Artigo & Atividade terapêutica & $\begin{array}{c}\text { Ano de } \\
\text { publicaçáo }\end{array}$ & Revista & Base de dados & Ensaios \\
\hline $\begin{array}{c}\text { Comparative study on the efficacy } \\
\text { of Allium sativum (garlic) in reduc- } \\
\text { ing some heavy metal accumulation } \\
\text { in liver of Wistar rats }\end{array}$ & $\begin{array}{l}\text { Extratos do alho exercem em } \\
\text { ratos efeito hepatoprotetor } \\
\text { contra absorção metais como } \\
\text { cádmio e mercúrio }\end{array}$ & 2012 & $\begin{array}{l}\text { Food and Chemical } \\
\text { Toxicology }\end{array}$ & Science Direct & $\begin{array}{l}\text { Pré- } \\
\text { clínicos in } \\
\text { vivo }\end{array}$ \\
\hline $\begin{array}{l}\text { Protective effect of allicin against } \\
\text { acrylamide-induced hepatocyte } \\
\text { damage in vitro and in vivo }\end{array}$ & $\begin{array}{l}\text { Composto extraído do alho, } \\
\text { alicina, mostrou efeito hepato- } \\
\text { protetor in vitro em cultura de } \\
\text { hepatócitos primários e também } \\
\text { in vivo no fígado de ratos }\end{array}$ & 2012 & $\begin{array}{l}\text { Food and Chemical } \\
\text { Toxicology }\end{array}$ & Science Direct & $\begin{array}{l}\text { Pré- } \\
\text { clínico in } \\
\text { vitro e in } \\
\text { vivo }\end{array}$ \\
\hline $\begin{array}{l}\text { Curcumin protects against } \\
\text { concanavalin A-induced hepatitis } \\
\text { in mice through inhibiting the } \\
\text { cytoplasmic translocation and } \\
\text { expression of high mobility group } \\
\text { box } 1\end{array}$ & $\begin{array}{l}\text { Composto curcumina, extraí- } \\
\text { do de Curcuma longa, atenuou } \\
\text { em ratos níveis de hepatite } \\
\text { induzida por concanavalina A }\end{array}$ & 2013 & Inflammation & Springer & $\begin{array}{l}\text { Pré- } \\
\text { clínico in } \\
\text { vivo }\end{array}$ \\
\hline $\begin{array}{c}\text { Protein dependent fate of hepatic } \\
\text { cells under nicotine induced } \\
\text { stress and curcumin ameliorated } \\
\text { condition }\end{array}$ & $\begin{array}{l}\text { Em ratazanas, curcumina } \\
\text { atenuou a hepatotoxicidade } \\
\text { induzida por nicotina }\end{array}$ & 2012 & $\begin{array}{l}\text { European Journal of } \\
\text { Pharmacology }\end{array}$ & Science Direct & $\begin{array}{l}\text { Pré- } \\
\text { clínico in } \\
\text { vivo }\end{array}$ \\
\hline $\begin{array}{l}\text { Glucose-regulated protein } 78 \\
\text { (GRP78) mediated the efficacy to } \\
\text { curcumin treatment on hepato- } \\
\text { cellular carcinoma }\end{array}$ & $\begin{array}{l}\text { Proteína regulada por glucose } \\
78 \text { (GRP78) encontrada na } \\
\text { curcumina, diminuiu a proli- } \\
\text { feração celular de carcinoma } \\
\text { hepatocelular (HCC) }\end{array}$ & 2011 & $\begin{array}{c}\text { Annals of Surgical } \\
\text { Oncology }\end{array}$ & Springer & $\begin{array}{l}\text { Pré- } \\
\text { clínico in } \\
\text { vitro }\end{array}$ \\
\hline $\begin{array}{l}\text { Knockdown survivin expression } \\
\text { reduces the efficacy of curcum- } \\
\text { in treatment in hepatocellular } \\
\text { carcinoma cells }\end{array}$ & $\begin{array}{l}\text { Níveis da expressão de } \\
\text { survivina medeiam a eficácia } \\
\text { terapêutica da curcumina su- } \\
\text { primindo células de carcino- } \\
\text { ma hepatocelular (HCC) }\end{array}$ & 2012 & $\begin{array}{c}\text { Annals of Surgical } \\
\text { Oncology }\end{array}$ & Springer & $\begin{array}{l}\text { Pré- } \\
\text { clínico in } \\
\text { vitro }\end{array}$ \\
\hline
\end{tabular}


Tabela 2: Continuação.

\begin{tabular}{|c|c|c|c|c|c|}
\hline Artigo & Atividade terapêutica & $\begin{array}{c}\text { Ano de } \\
\text { publicaçáo }\end{array}$ & Revista & Base de dados & Ensaios \\
\hline $\begin{array}{l}\text { Protective effect of curcumin } \\
\text { on N-nitrosodiethylamine and } \\
\text { carbon tetrachloride-induced } \\
\text { hepatocarcinogenesis in Sprague- } \\
\text { Dawley rats }\end{array}$ & $\begin{array}{l}\text { Diminuição do número } \\
\text { e do tamanho de focos } \\
\text { pré-neoplásicos induzidos } \\
\text { por N-nitrosodietilamina e } \\
\text { tetracloreto de carbono no } \\
\text { fígado de ratos, por meio do } \\
\text { bloqueio da degradação IкB- } \alpha\end{array}$ & 2012 & $\begin{array}{c}\text { Comparative } \\
\text { Clinical Pathology }\end{array}$ & Springer & $\begin{array}{l}\text { Pré- } \\
\text { clínico in } \\
\text { vivo }\end{array}$ \\
\hline $\begin{array}{l}\text { Hepatoprotective effects of } \\
\text { Cynara extract and silymarin on } \\
\text { carbon tetrachloride-induced } \\
\text { hepatic damage in rats }\end{array}$ & $\begin{array}{l}\text { Tratamento com extrato de } \\
\text { Cynara scolymus protege con- } \\
\text { tra lesóes hepáticas induzidas } \\
\text { por tetracloreto de carbono } \\
\text { (CCl4) em ratos }\end{array}$ & 2013 & $\begin{array}{c}\text { Comparative } \\
\text { Clinical Pathology }\end{array}$ & Springer & $\begin{array}{l}\text { Pré- } \\
\text { clínico in } \\
\text { vivo }\end{array}$ \\
\hline $\begin{array}{l}\text { Glycine soya diet synergistically } \\
\text { enhances the suppressive effect of } \\
\text { tamoxifen and inhibits tamox- } \\
\text { ifen-promoted hepatocarcino- } \\
\text { genesis in 7,12-dimethylbenz[ } \alpha] \\
\text { anthracene-induced rat mamma- } \\
\text { ry tumor model }\end{array}$ & $\begin{array}{c}\text { Dieta com sementes de } \\
\text { Glycine max potencializa } \\
\text { a eficácia terapêutica de } \\
\text { Tamoxifeno contra tumores } \\
\text { mamários e melhora a supres- } \\
\text { são da hepatocarcinogênese } \\
\text { em ratos }\end{array}$ & 2011 & $\begin{array}{c}\text { Food and Chemical } \\
\text { Toxicology }\end{array}$ & Science Direct & $\begin{array}{l}\text { Pré- } \\
\text { clínico in } \\
\text { vivo }\end{array}$ \\
\hline $\begin{array}{l}\text { Alpha-momorcharin possessing } \\
\text { high immunogenicity, immuno- } \\
\text { toxicity and hepatotoxicity in SD } \\
\text { rats }\end{array}$ & $\begin{array}{l}\text { Composto Alfa-momorcharin, } \\
\text { extraído a partir de sementes } \\
\text { de Momordica charantia, } \\
\text { apresentou imunogenicidade e } \\
\text { imunotoxicidade em ratos }\end{array}$ & 2012 & $\begin{array}{c}\text { Journal of } \\
\text { Ethnopharmacology }\end{array}$ & Science Direct & $\begin{array}{l}\text { Pré- } \\
\text { clínico in } \\
\text { vivo }\end{array}$ \\
\hline $\begin{array}{l}\text { Atividade hepatoprotetora dos } \\
\text { extratos etanólico e hexânico das } \\
\text { folhas de Momordica charantia }\end{array}$ & $\begin{array}{l}\text { Extratos hexânico e etanólico } \\
\text { das folhas de } M \text {. charantia } \\
\text { desempenharam potencial } \\
\text { hepatoprotetor e antioxidante } \\
\text { em modelos de lesão hepática } \\
\text { aguda induzida por etanol em } \\
\text { camundongos }\end{array}$ & 2010 & $\begin{array}{l}\text { Revista Brasileira de } \\
\text { Plantas Medicinais }\end{array}$ & SciELO & $\begin{array}{l}\text { Pré- } \\
\text { clínico in } \\
\text { vitro }\end{array}$ \\
\hline $\begin{array}{l}\text { The MAP30 protein from bitter } \\
\text { gourd (Momordica charantia) } \\
\text { seeds promotes apoptosis in liver } \\
\text { cancer cells in vitro and in vivo }\end{array}$ & $\begin{array}{l}\text { MAP30, componente natural } \\
\text { de } M \text {. charantia, suprimiu } \\
\text { a proliferação de células de } \\
\text { hepatocarcinoma (HepG2) e } \\
\text { também mostrou potencial } \\
\text { antitumoral em ratos com } \\
\text { tumor no fígado }\end{array}$ & 2012 & Cancer Letters & Science Direct & $\begin{array}{l}\text { Pré- } \\
\text { clínico in } \\
\text { vitro e in } \\
\text { vivo }\end{array}$ \\
\hline $\begin{array}{l}\text { Improved glycemic control, } \\
\text { pancreas protective and hepato- } \\
\text { protective effect by traditional } \\
\text { poly-herbal formulation "Qurs } \\
\text { Tabasheer" in streptozotocin } \\
\text { induced diabetic rats }\end{array}$ & $\begin{array}{c}\text { Formulação contendo flor } \\
\text { de Punica granatum exerceu } \\
\text { efeito hepatoprotetor em ratos } \\
\text { diabéticos }\end{array}$ & 2013 & $\begin{array}{c}\text { BMC } \\
\text { Complementary } \\
\text { and Alternative } \\
\text { Medicine }\end{array}$ & Springer & $\begin{array}{l}\text { Pré- } \\
\text { clínico in } \\
\text { vivo }\end{array}$ \\
\hline
\end{tabular}

Fonte: Dados da pesquisa, 2015.

Curcuma longa (açafrão) foi a planta com a maior concentração de estudos de interesse, tendo sido encontradas cinco publicaçôes: Tu et al. ${ }^{13}$, Banerjee et al. ${ }^{14}$, Chang et al. ${ }^{15}$, Hung et al. ${ }^{16}$ e El-Amir e Hassanein ${ }^{17}$.

Momordica charantia (melão-de-são-caetano) aparece em seguida, com três artigos científicos referindo algum nível de atividade hepatoprotetora a partir de sua análise, conforme estudos publicados por Meng et al. ${ }^{18}$, Pereira et al. ${ }^{12}$ e Fang et al. ${ }^{19}$.

Para Allium sativum (alho), foram encontradas duas publicaçôes de interesse: Nwokocha et al. ${ }^{20} \mathrm{e}$ Zhang et al. ${ }^{21}$.

Para as três demais espécies vegetais, Cynara scolymus, Glycine max e Punica granatum (romã), foram 
encontrados um estudo cada, sendo, respectivamente: Abdel-Salam et al..$^{22}$, Mishra et al. ${ }^{23}$ e Ahmed et al. ${ }^{24}$.

Destaca-se que essa triagem avaliou tão somente um período da produção científica após a criação da RENISUS, porém diversas espécies vegetais já tiveram seu potencial hepatoprotetor comprovado cientificamente, entre as quais destacamos, por exemplo: Achillea millefolium L. (mil-folhas), Yaeesh et al. ${ }^{25}$; Phyllanthus amarus Schum. \& Thonn. (quebra-pedra), Pramyothin et al. ${ }^{26}$; Vitis vinifera L. (uva), Sharma et al. ${ }^{27}$; Kalanchoe pinnata (Lam.) Pers. (folha-da-fortuna), Yadav e Dixit ${ }^{28}$; Equisetum arvense L. (cavalinha), Oh et al. ${ }^{29}$; Phyllanthus niruri L. (quebra-pedra), Harish e Shivanandappa ${ }^{30}$; e Aloe barbadensis Mill. (babosa), Chandan et al. ${ }^{31}$.

Para mais detalhes sobre os bioensaios realizados, as referências originais devem ser consultadas.

\section{Discussão}

Considerando que normalmente as plantas apresentam baixa toxicidade, muitas espécies podem ser utilizadas como adjuvantes terapêuticos no tratamento de doenças, inclusive as hepáticas. Porém, extensos estudos são necessários para determinar o potencial dessas plantas na prevençáo e terapia de doenças. Dessa forma, evitam-se os malefícios decorrentes do uso indevido, proporcionando um consequente aumento dos benefícios na utilização das plantas medicinais indicadas pela cultura popular ${ }^{32}$.

Assim, nesse curto período avaliado, observou-se que o açafrão foi a planta para qual foi encontrada a maior quantidade de pesquisas que relatam potencial hepatoprotetor. A curcumina é um pigmento responsável por várias atividades biológicas já comprovadas. Trata-se de um dos fitoquímicos ativos encontrados com elevada concentração em plantas das espécies Zingiberaceae ${ }^{33}$, o que explica a quantidade de trabalhos e resultados encontrados para Curcuma longa.

Estudos como os realizados por Girish et al. ${ }^{34} \mathrm{e}$ El-Maraghy et al..$^{35}$, por exemplo, demonstram que o açafrão já vem sendo estudado e possui propriedades terapêuticas eficazes e promissoras, especialmente no tratamento de doenças hepáticas. Esse cenário vem ao encontro dos resultados encontrados nesta revisão, sendo que $38,5 \%$ do total de artigos de interesse mencionam algum tipo de atividade terapêutica hepatoprotetora a partir do estudo com Curcuma longa.

Paralelamente, dos 13 estudos com potencial hepatoprotetor, cinco publicaçóes são relacionadas à supressão da hepatocarcinogênese $e^{15-17,19,23}$. Trata-se da terceira causa mais comum de mortalidade por câncer ${ }^{36}$, o que se presume justificar essa maior parcela de estudos.
Somente um trabalho dos 13 artigos de interesse foi realizado por pesquisadores brasileiros, sendo que, das seis espécies com trabalhos dentro do escopo da pesquisa, nenhuma é nativa do Brasil. Nesse sentido, explorar a biodiversidade pode contribuir para que a utilização de plantas medicinais por parte da populaçáo se torne uma área essencial no país, haja vista existir potencial econômico na flora brasileira a partir da descoberta de novos compostos derivados de produtos naturais ${ }^{37}$.

Diante do potencial terapêutico das plantas para o cuidado e promoçấo da saúde, desde 2012 o MS lança, anualmente, um edital para projetos de estruturação de Arranjos Produtivos Locais (APLs) voltados para plantas medicinais. O edital, lançado em agosto de 2015, destinou R\$ 4 milhóes para o Programa Nacional de Plantas Medicinais e Fitoterápicos (PNPMF) do $\mathrm{MS}^{38}$. No total, desde 2012, 66 projetos em todas as regióes do país já receberam recursos do MS, totalizando investimento superior a $\mathrm{R}$ \$ 26 milhóes ${ }^{39}$.

\section{Conclusão}

Avaliando os resultados apresentados, conclui-se que sáo poucos os trabalhos publicados nas bases de dados consultadas no período de análise que atribuem potencial hepatoprotetor por meio de estudos com plantas da RENISUS.

Entre as 71 plantas da lista da RENISUS, apenas para seis espécies foram encontrados estudos com potencial terapêutico. Destas, duas espécies são disponibilizadas no SUS como fitoterápicos, Cynara scolymus e Glycine max. Nesse contexto, a divulgação deste estudo permitirá refletir e ampliar a percepção acerca das políticas públicas de saúde e, desse modo, fornecer subsídios para realização de novas práticas de saúde destinadas à utilização consciente de fitoterápicos, bem como das plantas disponibilizadas à população através do Sistema Único de Saúde.

\section{Referências}

1. Adewusi EA, Afolayan AJ. A review of natural products with hepatoprotective activity. J Med Plants Res. 2010;4(13):1318-34.

2. Kumar CH, Ramesh A, Kumar JNS, Ishaq BM. A review on hepatoprotective activity of medicinal plants. Int J Pharm Sci Res. 2011;2(3):501-15.

3. Harish R, Shivanandappa T. Antioxidant activity and hepatoprotective potential of Phyllanthus Niruri. Food Chem. 2006;95(2):180-5.

4. World Health Organization. Fact sheet no 204 [Internet]. 2015 [acesso em 2016 ago 01]. Disponível em: http://www. who.int/mediacentre/factsheets/fs204/en/ 
5. Lozano R, Naghavi M, Foreman K, Lim S, Shibuya K, Aboyans V, et al. Global and regional mortality from 235 causes of death for 20 age groups in 1990 and 2010: a systematic analysis for the Global Burden of Disease Study 2010. Lancet. 2012;380(9859):2095-128.

6. Kapur V, Pillai KK, Hussian SZ, Balani DK. Hepatoprotecitve activity of "jigrine" on liver damage caused by Alcohol-Carbon tetrachloride and paracetamol in rats. Indian J Pharmacol. 1994;26:35-40.

7. Sotelo-Félix JI, Martinez-Fong D, Muriel D, Santillán RL, Castillo D, Yahuaca P, et al. Evaluation of the effectiveness of Rosmarinus officinalis (Lamiaceae) in the alleviation of carbon tetrachloride induced acute hepatotoxicity in rats. J Ethnopharmacol. 2002;81(2):145-54.

8. Levy C, Seeff LD, Lindor KD. Use of herbal supplements for chronic liver disease. Clin Gastroenterol Hepatol. 2004;2(11):947-56.

9. Newman DJ, Cragg GM. Natural products as sources of new drugs over the 30 years from 1981 to 2010. J Nat Prod. 2012;75(3):311-35.

10. Brasil. Ministério da Saúde. Portal da Saúde: Relação Nacional de Medicamentos Essenciais (RENAME) [Internet]. 2013 [acesso em 2016 ago 01]. Disponível em: http://bvsms.saude.gov.br/bvs/saudelegis/gm/2012/ prt0533_28_03_2012.html

11. Brasil. Ministério da Saúde. Portal da Saúde: Programa Nacional de Plantas Medicinais e Fitoterápicos [Internet]. 2009 [acesso em 2016 ago 01]. Disponível em: http:// portalsaude.saude.gov.br/images/pdf/2015/janeiro/05/ programa-nacional-plantas-medicinais-fitoter--picos-pnpmf.pdf

12. Pereira BS, Nunes-Pinheiro DCS, Vasconcelos AKP, Pinheiro ADN, Rodrigues PA. Atividade hepatoprotetora dos extratos etanólico e hexânico das folhas de Momordica charantia. Rev Bras Plantas Med. 2010;12(3):311-6.

13. Tu CT, Yao QY, Xu BL, Zhang SC. Curcumin protects against concanavalin $\mathrm{A}$-induced hepatitis in mice through inhibiting the cytoplasmic translocation and expression of high mobility group box 1 . Inflammation. 2013;36(1):206-15.

14. Banerjee S, Chattopadhyay K, Chhabra JK, Chattopadhyay B. Protein dependent fate of hepatic cells under nicotine induced stress and curcumin ameliorated condition. Eur J Pharmacol. 2012;684(1-3):132-45.

15. Chang YJ, Tai CJ, Kuo LJ, Wei PL, Liang HH, Liu TZ, et al. Glucose-regulated protein 78 (GRP78) mediated the efficacy to curcumin treatment on hepatocellular carcinoma. Ann Surg Oncol. 2011;18(8):2395-403.

16. Hung CS, Liu HH, Huang MT, Cheng CW, Kuo LJ, Ho YS, et al. Knockdown survivin expression reduces the efficacy of curcumin treatment in hepatocellular carcinoma cells. Ann Surg Oncol. 2012;19(11):3547-55.

17. El-Amir YO, Hassanein KMA. Protective effect of curcumin on $\mathrm{N}$-nitrosodiethylamine and carbon tetrachloride-induced hepatocarcinogenesis in Sprague-Dawley rats. Comp Clin Path. 2012;22(4):631-6.

18. Meng Y, Liu B, Lei N, Zheng J, He Q, Li D, et al. Alphamomorcharin possessing high immunogenicity, immunotoxicity and hepatotoxicity in SD rats. J Ethnopharmacol. 2012;139(2):590-8.

19. Fang EF, Zhang CZ, Wong JH, Shen JY, Li CH, Ng TB. The MAP30 protein from bitter gourd (Momordica charantia) seeds promotes apoptosis in liver cancer cells in vitro and in vivo. Cancer Lett. 2012;324(1):66-74.

20. Nwokocha CR, Owu DU, Nwokocha MI, Ufearo CS, Iwuala MO. Comparative study on the efficacy of Allium sativum (garlic) in reducing some heavy metal accumulation in liver of Wistar rats. Food Chem Toxicol. 2012;50(2):222-6.

21. Zhang L, Zhang $\mathrm{H}$, Miao $\mathrm{Y}$, Wu S, Ye H, Yuan Y. Protective effect of allicin against acrylamide-induced hepatocyte damage in vitro and in vivo. Food Chem Toxicol. 2012;50(9):3306-12.

22. Abdel-Salam OME, Sleem AA, Shafee N. Hepatoprotective effects of Cynara extract and silymarin on carbon tetrachloride-induced hepatic damage in rats. Comp Clin Pathol. 2013;23(3):709-16.

23. Mishra R, Bhadauria S, Murthy PK, Murthy PS. Glycine soya diet synergistically enhances the suppressive effect of tamoxifen and inhibits tamoxifen-promoted hepatocarcinogenesis in 7,12-dimethylbenz $[\alpha]$ anthracene-induced rat mammary tumor model. Food Chem Toxicol. 2011;49(2):434-40.

24. Ahmed D, Sharma M, Mukerjee A, Ramteke PW, Kumar V. Improved glycemic control, pancreas protective and hepatoprotective effect by traditional poly-herbal formulation "Qurs Tabasheer" in streptozotocin induced diabetic rats. BMC Complement Altern Med. 2013;13:10.

25. Yaeesh S, Jamal Q, Khan AU, Gilani AH. Studies on hepatoprotective, antispasmodic and calcium antagonist activities of the aqueous-methanol extract of Achillea millefolium. Phytother Res. 2006;20(7):546-51.

26. Pramyothin P, Ngamtin C, Poungshompoo S, Chaichantipyuth C. Hepatoprotective activity of Phyllanthus amarus Schum. et. Thonn. extract in ethanol treated rats: in vitro and in vivo studies. J Ethnopharmacol. 2007;114(2):169-73.

27. Sharma SK, Suman, Vasudeva N. Hepatoprotective activity of Vitis vinifera root extract against carbon tetrachloride-induced liver damage in rats. Acta Pol Pharm. 2012;69(5):933-7.

28. Yadav NP, Dixit VK. Hepatoprotective activity of leaves of Kalanchoe pinnata Pers. J Ethnopharmacol. 2003;86(2-3):197-202.

29. Oh H, Kim DH, Cho JH, Kim YC. Hepatoprotective and free radical scavenging activities of phenolic petrosins and flavonoids isolated from Equisetum arvense. J Ethnopharmacol. 2004;95(2-3):421-4. 
30. Harish R, Shivanandappa T. Antioxidant activity and hepatoprotective potential of Phyllanthus niruri. Food Chem. 2006;95(2):180-5.

31. Chandan BK, Saxena AK, Shukla S, Sharma N, Gupta DK, Suri KA, et al. Hepatoprotective potential of Aloe barbadensis Mill. against carbon tetrachloride induced hepatotoxicity. J Ethnopharmacol. 2007;111(3):560-6.

32. Gurib-Fakim A. Medicinal plants: traditions of yesterday and drugs of tomorrow. Molecular Aspects of Medicine. 2006;27(1):1-93.

33. Golan DE, Armstrong EJ, Armstrong AW, Vahle JL, Tashjian JAH. Princípios de Farmacologia: a base fisiopatológica da farmacoterapia. 2a ed. Rio de Janeiro: Guanabara Koogan; 2009. 908 p.

34. Girish C, Koner BC, Jayanthi S, Ramachandra Rao K, Rajesh B, Pradhan SC. Hepatoprotective activity of picroliv, curcumin and ellagic acid compared to silymarin on paracetamol induced liver toxicity in mice. Fundam Clin Pharmacol. 2009;23(6):735-45.

35. El-Maraghy SA, Rizk SM, El-Sawalhi MM. Hepatoprotective potential of crocin and curcumin against iron overload-induced biochemical alterations in rat. Afr J Biochem Res. 2009;3(5):215-21.

36. Feitelson MA, Sun B, Tufan NLS, Liu J, Pan J, Lian Z. Genetic mechanisms of hepatocarcinogenesis. Oncogene. 2002;21(16):2593-604.

37. Brito SCD. Os efeitos do marco regulatório sobre a competitividade da cadeia produtiva de medicamentos fitoterápicos no Brasil [dissertação]. Palmas: Fundação Universidade Federal de Tocatins; 2010.

38. Brasil. Ministério da Saúde. Portal da Saúde. Saúde dobra investimento em projetos de produção de plantas medicinais e fitoterápicos. [Internet]. 2013 [acesso em 2016 ago 01]. Disponível em: http://portalsaude.saude.gov.br/images/pdf/2014/julho/09/edital-sctie-1-2014-disposicoes-gerais-apl.pdf

39. Brasil. Ministério da Saúde. Portal da Saúde. [Internet]. Edital SCTIE no 2, de 24 de agosto de 2015. [acesso em 2016 ago 01]. Disponível em: http://portalsaude.saude. gov.br/images/pdf/2015/agosto/26/edital-sctie-2-2015-disposicoes-gerais.pdf

\section{Como citar este artigo:}

Marmitt DJ, Rempel C, Goettert MI, Silva AC. Potencial hepatoprotetor das plantas medicinais da renisus: revisão sistemática. Rev. Aten. Saúde. 2016;14(49):84-91. 